This article was downloaded by: [Stanford University Libraries] On: 02 July 2012, At: 08: 18

Publisher: Taylor \& Francis

Informa Ltd Registered in England and Wales Registered Number: 1072954 Registered office: Mortimer House, 37-41 Mortimer Street, London W1T 3J H, UK

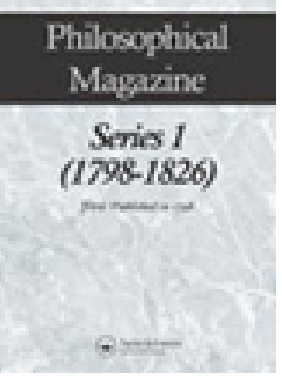

\title{
Philosophical Magazine Series 1
}

Publication details, including instructions for authors and subscription information: http:// www. tandfonline.com/loi/tphm12

XXIII. Anatomical observations on the crocodile of the Nile E. Geoffroy

Version of record first published: 18 May 2009

To cite this article: E. Geoffroy (1803): XXIII. Anatomical observations on the crocodile of the Nile, Philosophical Magazine Series 1, 16:62, 136-146

To link to this article: http:// dx. doi.org/ 10.1080/ 14786440308676315

\section{PLEASE SCROLL DOWN FOR ARTICLE}

Full terms and conditions of use: http://www.tandfonline.com/ page/terms-and-conditions

This article may be used for research, teaching, and private study purposes. Any substantial or systematic reproduction, redistribution, reselling, loan, sub-licensing, systematic supply, or distribution in any form to anyone is expressly forbidden.

The publisher does not give any warranty express or implied or make any representation that the contents will be complete or accurate or up to date. The accuracy of any instructions, formulae, and drug doses should be independently verified with primary sources. The publisher shall not be liable for any loss, actions, claims, proceedings, demand, or costs or damages whatsoever or 
howsoever caused arising directly or indirectly in connection with or arising out of the use of this material. 
The comanittee, adverting to $\mathrm{Mr}$. Telford's suggestion of an examination of Mr. Donaldson, called him before them; but found that he had never travelled any part of the country from Fort Augustus, westward, to Bernera or the lochs, and that his information was solely, as to that part of the country, derived from others.

A true copy from the record.

(Signed) Lewis Gordon, dep. sec.

XXIII. Anatomical Observations on the Crocodile of the Nile. By E. Geoffroy.

$T_{\text {HE following observations were read in the last sitting }}$ of the Institute of Egypt:-Two unfortunate combats, and the loss of the battle of the 3oth of Ventose, year 9, yave us reason to apprehend that the enemy, favoured by the misunderstanding which prevailed between our chiefs, would at length tear from us the most valuable of our colonies, which had cost us so many efforts and sacrifices; in a word, that celebrated country Egypt, which we had explored in every direction, which we had seen covered with monuments coeval with the heroic ages, and the fertility of which had appeared to us superior to its reputation. At the moment when we were informed of our disasters, and when the report circulated of them immediately excited against us the whole population of Egypt, a crocodile was brought to me which had been carried alive to Cairo, and which had died three days before. At a more fortunate period I had ardently desired to dissect an animal so much celebrated by antient authors; but being at that time abandoned to those painful sensations which all the French experienced, I hesitated a moment whether I should undertake this labour. Foreseing, however, that if I let slip this opportunity I might never have another, and being persuaded, as I always have been, that the courage proper for travellers placed in the same circumstances as those in which I then found -myself $f_{2}$ is that of resignation, I paid no attention to any thing but the crocodile then before me. But I was not able to proceed to a regular dissection, nor to extend my reseasches to all those organs which appeared to he warthy of natice. being prevented by a commencement of putrefaction which the crocodile had already experienced, and by the obligation I was under to save and to preserve the skin. Besides, as it had already been abserved

* From Annales du Museum d'Histoire Naturelle, No. 7. 
by several distinguished anatomists, I thought it sufficient to confine myself to the consideration of the organs which might bave escaped their examination; so that what I now publish contains only some additions to the history of an animal known since the earliest ages.

\section{Of the Manner in which the Jaws are moved.}

Who could believe, considering the present state of science, that this question is still problematical? It has been combated by a great number of travellers and naturalists, but none of them, as will be seen, have completely solved it.

Herodotus is the first who asserts that the crocodile is the only known animal whose upper jaw is moveable on the lower, which remains fixed : his opinion has been followed by all the antients. Aristotle, Pliny, \&c., and some of the moderns, such as Margrave, Oligerus, Jacobæus, Marmol, the illustrious Vesalius, and some Jesuit missionaries to Siam, who had an opportunity of seeing living crocodiles, or of examining them soon after death, all speak of them in the same terms; but little attention was paid to these testimonies. The first anatomists of the Academy of Sciences undertook to demonstrate the impossibility of the fact advanced by Herodotus, and the names of Perrault and Duverney tended to establish this opinion, which has been adopted by the naturalists who have since written on the crocodile.

It is no doubt very surprising that Perrault, known for his accuracy, and who carefully dissected a crocodile from the menagerie of Versailles, did not pay sufficient attention to the singular conformation of the head of this animal; and that he should have opposed with so much violence the opinion of the antients. He gives a minute description of the articulation of the jaws, without observing that it furnishes proofs against the fact which he proposed to establish ; and he besides supposed that he had done it in a satisfactory manner by rectifying the errors of Marmol, which he falsely ascribed to Vesalius, and by proving, with reason, that the upper jaw is not, as in perroquets, separated from the cranium, but that it forms with the rest of the head one osseous piece.

Since men of such merit as Perrault, Duverney, and the other naturalists who have since examined crocodiles in collections, could doubt of a fact attested by so great a number of observers, this question must certainly be embarrassed by a difficulty which can be cleared up ouly by an exact description of the head, and of the organs by which it is moved. 
The question here is not merely to rectify an accredited error, and to defend the antients from the injustice dome them by some of the noderns. I must also call the attention of naturalists to a singular fact in regard to organization. Nothing, indeed, can be more paradoxical than the head of the crocodile; all those parts which in other animals are on the sides, are in the crocodile thrown backwards. The temporal bone itself projects backwards a good deal beyond the cranium : it is elongated, and transtormed into a double condyle, the functions of which it performs. Every thing has in some measure been said of the head of the crocodile, by considering it as composed merely of two jaws, for the cranium is so small and so displaced that it escapes the first examination. It is found below and a little before the occipital plate; the brain, or rather the ganglion, contained in its cavity, which is exceedingly narrow, is continued pretty far forwards, so that the organs of sight and of hearing are situated below and a little behind it.

Another anomaly equally worthy of remark is, ist, That the lower jaw is a sixth longer than the upper and the cranium. 2d, That the lower jaw exhibits a cavity with two facets, where the horns of the temporal bone are articulated by a ginglymus. $3 \mathrm{~d}$, That the occipital condyle is on the same line as the four condyles of the temporal bones, so that the head is really retained towards its points of articulation as the lid of a box is by its hinge. 4th, That as the two jaws have only a simple motion from the top downwards, they cannot be moved separately to the right or to the left, to subject the aliments to a sort of trituration.

On examining a living crocodile, or one prepared, as is customary in collections, it is hardly possible to believe that the head terminates at the extremity of the jaws; one looks for the osseous box which contains the brain, and which in all other animals manifests itself externally under the form of a frontal protuberance. The observer thinks he sees it towards the anterior part of the neck, which is symmetrically swelled up, and which is generally taken for the complement of the head: but this swelling arises from the presence of the crotaphite muscles, which are pretty voluminous, and which in a great measure are lodged between the straight and oblique muscles.

Differences so great in the form of the head necessarily occasion others in the organs which correspond directly with it; and it is indeed found that the cervical column is composed of seven vertebra, which are distinct, but combined in their articulation in such a manner that they are 
not moveable on each other. The apophyses of these verebræ are so multiplied, so long, and so close to eacli other, that the animal cannot bend its neck, and that the cervical column, in regard to its uses, must be considered as one bone. The straight and oblique muscles attached to it, and which have their second point of insertion towards the occipital ridge, raise up when they contract the head on the neck, by making it describe an arch of $45^{\circ}$. The skin is thin behind the occipital plate, and readily yields to all the movements given to the head: on the other hand, the lower jaw is, as it were, sheathed in a rugous and very little flexible skin. If we suppose a muscular force sufficiently strong to draw it downwards, it would be retained by its coverings : it is besides confined towards its posterior extremity ; for the long apophysis situated beyond the articular facets approaches the skin by describing a curve exactly towards the point, where it is armed with a long scale. The latter opposes an almost invincible resistance to the elevation of the condyle, and consequently to the depression of the jaw : it is not however entirely fixed, especially in the manner understood by Marmol, who thought that it formed with the sternum one bone. Two small elongated muscles, by contracting, can give it a slight motion. The assertion of Herodotus, then, is almost strictly true: " The crocodile is the only animal known, whose upper jaw, between the branches of which is comprehended the cranium, is moveable on the under, which has a motion almost insensible."

\section{Of the Organs of Digestion.}

The antients, and almost all the moderns, have stated that the crocodile has no tongue: it is indeed true that it does not appear outwardly, but, speaking in a physiological point of view, this animal is not destitute of a tongue. The whole skin comprehended between the branches of the lower jaw is clothed interiorly with spongy, thick and flabby flesh, which is inseparably attached to it throughout its whole extent : but this muscle or tongue is in some measure masked in the inside by a continuation of the general coverings. It is a yellowish shagreened skin, perfectly similar to that of the palate: it is pierced with a great number of small holes, which are the orifices of the glands with which the upper part is furnished. This tongue has the form of the head of a lance: iis dimensions in the subject I examined, which was 2.10 metres long, was 0.15 in length by 0.05 at the rof. "Though it does not project forwards, I have no doubt that it serves to retain and convey the aliments into the ceso- 
phagas; for it is fixed by its base to the broad piece of the w hyoides. When the latter then is drawn downwards, while the muscular fitores of the tongue at the same time contract, it forms itself into a ball, and, being drawn backwards by the muscles of the os hyoides, it mecessarily carries with it in the contrary movement the aliments comprehended between it and the palate.

The os hyoides is composed of three pieces. The largest 0.10 metre by 0.07 is cartilaginous, and resembles the broad part of a wooden shovel : the posterior bottom is round, and the interior straight. The latter is inflected on the convex surface of the large piece, and it is in the groove formed by this inflection that the root of the tongue is inserted. It results from this disposition that the large piece projects beyond the root of tize tongue by about a centimetre. This projecting edge or kind of ridge becomes a velum, which, when the os hyoides is carried backwards, closes the whole of the back part of the mouth, and sonetimes also the posterior apertures of the nostrils.

Such is the mechanism which allows the crocodile when pursued and frightened, as I have had occasion to observe in Upper Egypt, to shelter itself, and to lie concealed in the river, and to be able to respire in it. It only thrusts out of the water the extremity of its muzzle where the nasal apertures are situated: the jaws are then open, without the water being able to penetrate into the cesophagus and trachea.

The horns of the os hyoides are two small arched and elongated bones about 0.07 metre in length.

The os hyoides is drawn backwards by four museles, the exterior ones of which are round and the interior flat: it is drawn forwards by the contraction of the tongue.

Perrault gives to the cesophagus of the young crocodile which he examined a greater diaineter than to the stomach. He compares the cesophagus of this reptile to the gizzard of a bird which feeds on grain; and he consequently supposes, what would be an anomaly too monstrous to be found in the animal oconomy, that digestion is effected in a great measure in the cesophagus. My observations are directly contrary to those of that celebrated anatomist. I found the diameter of the cesophagus to be 0.86 metre, and that of the stomach 0.17 by 015 ; for the form of this bag is that of an ellipsoid slightly compressed on the sides: 'in a word, it did not appear to me to have any resemblance to a girzard. The velvety tunic was exceedingly thick; the muscular fort was less so: the inside was filled with a quantity of small 
pebbles, the polish of which announced that they had served for the trituration of the alimentary matters. The stomach had over it a bag, which was terminated by the pylorus. In the intestines, which were $3 \cdot 67$ metres in length, nothing could be distinctly observed but the rectum, in eonsequence of its great thickness. The duodenum, a little below the pylorus, was remarkable by a double contour, which it made from the top upwards for the extent of $0^{\cdot 14}$ : its folds, which touched each other, were united by an adipose membrane split in three different places. The rest of the intestines, in which no trace of a cœecum is observed, was strongly attached to the loins by means of the mesentery.

\section{Organs of Respiration.}

The flatness of the tail of the crocodile, and the membranes extended. between the toes of its hind feet, suffciently account for the decided taste which this animal has: for rivers; but as the ears and back part of the mouth are each provided with a cartilage, which, when necessary, prevents the introduction of the surrounding liquid, I had reason to expect a similar relation between the pulmonary organs and those of natation. I therefore always wished that I might be able to describe these pulmonary organs as compared with those of other lizards, in order to trace out the most essential anatomical characters by which the genus of the crocodile differs from various other families of reptiles. If I therefore give this description, it is not because most of the preceding anatomists have omitted to do it : on the contrary, we are acquainted with those of Vesalius, sir Hans Sloane, Perrault, Hasselquist, and that more minute by the Jesuit missionaries to Siam, to which Duverney has added, and which might be considered as complete.

The trachea opens in the centre of the broad piece of the os hyoides, and accompanies it backwards nearly (that I may employ the comparison already. used) as the handle of a wooden shovel accompanies the lower part. A little before it divides itself into two branches, it is folded back, and turns to the right side, as is observed in several birds. Its length in a straight line, as far as the point of its bifurcation, is 0.38 metre. It is composed of complete, broad, cartilaginous rings, separated from each other by a very narrow membranous ring. I found only the first ten rings. complete. Duverney, in the crocodile of the Academy, counted sixteen, the portions of which were united by a membrane. The Jesuits above mentioned found a greater number in the crocodiles of Siam. It is this membrane strongly 
strongly distended, and made to vibrate in the manner of the parchment of a drum, by the interior air of the lungs, which causes the crocodile to emit that cry, or rather that bellowing noise, mentioned by Catesby, La Coudreniere, and Bastram. The fissure of the glottis is then shut by the muscular roll which borders it on each side.

The lungs are two conical bags, the summits of which are turned towards the head. Their interior surfaces, which rest on the cesophagus, retain the impression of it by a longitudinal furrow. Their length is 0.33 metre, and their breadth at the base 0.22 . The figure given by Perrault represents them of an elongated ovoid form.

The lungs of lizards are only two elongated bags, 0.40 in length, and 0.11 in their greatest thickness; the interior sides of which are lined with small reticular carneous fibres and sanguiferous vessels. Those of crocodiles differ by the size of the membranous leaves with which they are furnished, and which form as it were several small walls. It is a vast reticulation, composed of a quantity of meshes similar to those whish are seen in the second stomach of ruminating animals. Each of these meshes is the edge and entrance of a small bag, which opens into a second, and sometimes into a third. They are composed of two kinds of fibres : the first circular, and parallel to each other; the second perpendicular, which transversely intersect the former at right angles. The centre of each pulmonary bag, entirely empty, serves in some measure as a receptacle for the air. The cells in opening become filled with it. They then compress it by shutting, and convey it to the blood, as we may say, without the concurrence of those organs which press on the whole pulmonary mass. They repeat this play until the air contained in the whole lung is vitiated. The crocodile, then, is not forced to come and respire at the surface of the water till after a certain time has elapsed. This structure of the lungs, which makes the crocodile deviate from lizards, brings it near to the sea-tortoise. I shall have occasion hereafter to remark, that this is not the only relation which it has to these animals.

\section{Of the Organs of Generation.}

These organs are so complex, and have so little relation to what is known in the mammalia, that authors, as we may say, have been afraid to describe them, and have scarcely given a slight sketch of them. It has been said that the crocodile is only a lizard of a monstrous size, and Linnzus has consequently arranged it in his system under the genus 
lacerta. What I have already said of the configuration of the head and lungs of this reptile removes it no doubt from that genus, but the consideration of the organs of generation will obviate all uncertainty in regard to these natural relations.

Most lizards, like serpents, are furnished with two yards, situated on each side of the anus. Properly speaking, they are only two cavernous bodies, formed by a slight cutaneous expansion, and terminated by two cartilaginous appendices. In the inside of them are found two glands, which pour forth a liquor in such abundance, that it has given rise to mistakes in regard to its nature, and made it be considered as the seminal liquor. These yards move in a sheath formed by a duplicature of the skin : they are terminated behind by an elongated muscle, always inclosed in a membranous vagina, which, by contracting, forces them to reenter.

If the crocodile retains any part of this general plan of organization, the combination is quite different. It has only one yard lodged at the anterior part, and in the fold of a common cloaca: it is imperforated, entirely cartilaginous, and terminated by a kind of gland 0.03 in length. It has two glands on the sides of the anus, from which oozes a whitish liquor through two distinct orifices at a considerable distance from each other. These glands produce no protuberance, and yet the retractor of the cavernous bodies of lizards exists. It is even of so considerable a volume ( 0.40 in length, and 0.11 in its greatest thickness), that it is this muscle with its congenerate that swells up the anterior part of the tail, so that it cannot be distinguished by a diminution of volume from the rest of the body. This muscle is terminated by a sharp edge, or ridge, where it is articulated with the caudal vertebræ, and by a free and round edge on the opposite side. What is remarkable besides is, that it is contained, like the retractor muscle of the cavernous bodies, in a proper sheath of great thickness, and of a cartilaginous nature. This sheath is continued forwards in an aponeurosis, which spreads and is inserted on the pelvis; so that, as the uses of this muscle change with the general system of organization, they are confined to contributing merely to the lateral motion of the tail.

The testicles in some measure approach near to those of fishes: they are narrow and elongated. They are observed a little above and before the kilneys.

The semen is conveyed in two pretty large vessels, contiguous, and lodged behind the common cloaca. These vesicles are in part closed by a cartilaginous bag : they open 
into the eommen cloaca by six or seven holes on each side, disposed in a circular manner around the urinary passage.

\section{Of the Liver.}

The liver is composed of two unequal lobes : one of them has the form of a parallelopipedon $\left(0^{*} 14\right.$ metre by $\left.0^{\circ} 09\right)$; the other is slender and more elongated $(0 \cdot 19)$. This viscus exhibited a very remarkable organization, which has never yet been noticed by any anatomist. The convex surface of each lobe is covered by a membrane, which is the aponeurosis of a muscle, the use of which I can hardly comprehend. This muscle, which begins at the posterior and inferior edge of each lobe, is inserted very near the pelvis, in the last piece of the sternum; for it must be recollected, that the latter is prolonged beyond the ribs, and terminates in a large piece articulated with the bones of the pelvis. These two muscles, which have not yet been found in any other animal, produce by their contraction the depression of the liver, and thereby give more capacity to the breast. This use makes them have an affinity with the diaphragm : the points to which they are attached-might induce a belief of the same thing * The gall-bladder is ovoid, 0.08 of a metre by 0.03 , and adheres: to the right lobe of the liver.

\section{Of the other Viscera.}

As these have been already so well described by most of the authors before mentioned, I shall give only their relative positions, because this information may furnish some useful hints for determining the different kinds of crocodiles.

The heart.-Its height is 0.07 metre, its base 0.05: The right auricle is larger than the left.

The spleen. $\rightarrow$ Oval elongated, or10 by 0.04 . On the inferior face it is somewhat concave; and on the upper rises into two ridges, ane of which is veryt small.

The kidneys are composed of papillæ, and numerous sinuosities. formed by a collection of glands, 0.11 metre by $0 \cdot 05 \frac{x}{2}$.

I had not resolved to publish these observations till after my return from Egypt; and at that time, notwithstanding the learned researches of several of my colleagues, they had still retained all their novelty. The object of Cuvier's excellent memoir is merely to establish the real differences be-

* C. Cuvier observed these muscles in the crocodile of St. Domingo. Ife proposes to describe them at more length in his Comiparative Anatatsp. 
tween the crocodiles of the new continent and those of the old ; and Daudin * has endeavoured, in particular, to enrich the history of the crocodile from the relations of travellers before unknown.

Since I have occasion to quote the latter work, I must rectify an error which concerns me, and which C. Daudin introduces in consequence of the respect which he is pleased to entertain towards me. He announces that " $I$ attempted, during my stay in Egypt, to tame crocodiles after the example of the antients, and that my attempts were not crowned with that success which I expected." It is a duty which I owe to truth, to assert that I never made any attempt of the kind.

The following is the circumstance that gave rise to this report, which was indeed circulated at the time of our triumphs. The period when the army of the East had at its head a chief worthy of its great exploits, the English sent to combat us could then find no opportunity of gratifying the desire of injuring us with which they were tormented. Tired of cruising backwards and forwards to no purpose, they wished to amuse themselves, and thought they could reach us with very feeble weapons, by endeavouring to turn into ridicule the principal persons in the army. They made some caricatures, which they sent to England, and which were thence conveyed to France. I had the honour of attracting their notice. They introduced into the scene several crocodiles; and this ephemeron production gave rise to the mistake to which I allude.

\section{Explanation of the Figures. (Plate III.)}

Fig. 1. A A, the lungs.

$B$, the pericardium.

C C, the two lobes of the liver.

D, the diaphragmatic muscles.

E, the stomach.

$\mathrm{F}$, the intestinal canal.

$G$, the sternum and its muscles seen interiorly.

$\mathrm{H}$, the same organs seen exteriorly.

Fig.2. The cranium of the crocodile of the Nile. It is here represented,

1 st, To give an idea of the manner in which the crocodile raises its upper jaw on the inferior.

2dly, To show the two condyles of the horns of the temporal bone, and the cavity with two facets, where they are articulated.

* Traip de Repliles, forming a continuation of the works of Buffon. VoL. XVI. No. 62 . 
Philo.Jfag Pl III.Vel.XVI.

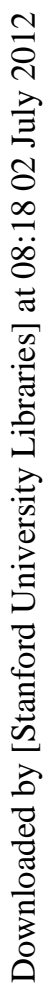

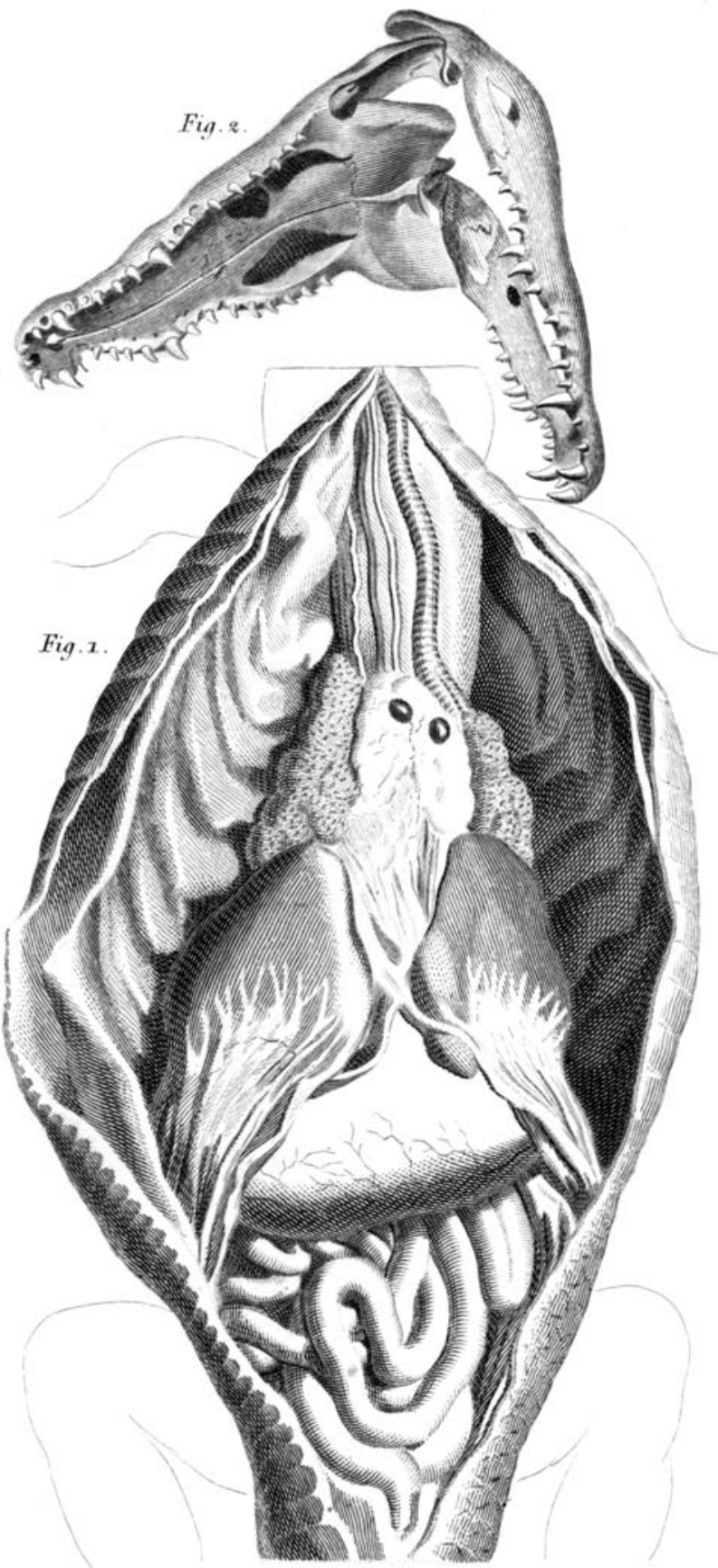


3dly, To render sensible the differences which exist between the large teeth of the crocodile of the Nile and those of the crocodile of St. Domingo.

XXIV. Olservations and Experiments on the Light emitted by rotten Wood, in the different Kinds of Gas, and in Fluids. By C. W. Böckmax, of Carlsruhe.

[Concluded from p. 26.]

\section{Experiment XVII.}

I introducen phosphorescent wood under the receiver of the air-pump, placed a bit of it in a glass filled with water, and another picce on a dish not immersed in water. When the air began to be rarefied, a quantity of air not inconsiderable issued from the wood. The light of the wood seemed to be somewhat weaker than at first, and proportionably less than that of a piece placed without the receiver. When the quicksilver in the barometer connected with it sunk about tour lines, on the re-admission of atmospheric air 1 thought I observed a considerable increase in the phosphorescence. The piece of wood immersed in water was entirely penetrated by that fluid: it therefore fell to the bottom, but emitted as strong a light as at first. This experiment was several times repeated with the same result.

\section{Experiment XVIII.}

Oval glass flasks, capable of containing five cubic inches, and of equal thickness, were filled; some with oxygen gas, some with azotic gas, and some with carbonic acid gas, and well stopped with corks, to which were affixed wires supporting pieces of phosphorescent wood. I then introduced all these vessels at the same time into water at $70^{\circ}$ of Reaumur. In about three-quarters of a minute the light in the carbonic acid gas perceptibly decreased, and then that in the azotic gas; in one minute and a half it appeared weaker in the oxygen gas; and in two minutes and a half the least phosphorescence was not to be observed in any of the vessels. It could not afterwards be revived in any of the pieces of wood by any means whatever. This experiment was also repeated several times with the like result.

\section{Experiment XIX.}

Rotten wood emitted light in spring water, in boiled water, and in distilled water, kept in a close vessel till the experi- 